\title{
Evaluation of Accessibility Measures in Practitioner Policy and Their Effectiveness in Non-Metropolitan Areas
}

\author{
Brett Williams ${ }^{\mathrm{a}^{*}}$ \\ Pascal Perez
}

\begin{abstract}
Various accessibility measures exist to explore the performance of transport by quantifying the opportunities available at a particular, discrete location and the available means to travel both to and from these opportunities. In Australia there is currently no consistent performance measure used by regulatory authorities to evaluate accessibility in order to inform land-use planning decisions. Considering the widespread availability and usage of strategic transport modelling software, a unified accessibility metric would benefit practitioners when planning for future infrastructure needs. Furthermore, the development of accessibility measures has tended to focus on metropolitan areas without widespread exploration of their effectiveness in regional and rural areas, where public transport, walking and cycling opportunities are limited due to lower population densities and wider disaggregation of localities. This paper provides a review of the existing literature on accessibility performance measures, and identifies areas of potential research on transport accessibility in nonmetropolitan areas, with the aim to improve the planning and delivery of future infrastructure needs in an optimised and sustainable manner.
\end{abstract}

Key words: Accessibility; Land use planning; Local government; Nonmetropolitan areas; Policy; Transport

\section{Introduction}

Many local government authorities have received criticism for a lack of strategic vision towards urban development and inadequate provision of transport infrastructure. While geographic and historical legacies often hinder genuine attempts to develop such a strategic vision, evidence suggests that traffic congestion, ineffective and under-utilised public transport, and inadequate road infrastructure stem from inefficient connectivity between land use and transport systems. This paper discusses a proposal to evaluate connectivity through a single indicator: the level of accessibility.

Austroads ${ }^{1}$ defines accessibility as 'the variety of opportunities provided to people through efficient arrangement of land use and various modes of transport'. Accessibility can be used to compare one particular location to another in terms of the opportunities available and means to travel to and from these opportunities. This information can in turn be used to analyse how effective an area is in terms of how it connects to its surrounding area, or how accessible it is. Accordingly planning authorities can target areas of good accessibility by

\footnotetext{
${ }^{a}$ Shoalhaven City Council, Nowra NSW 2541, Australia

${ }^{\mathrm{b}}$ SMART Infrastructure Facility, University of Wollongong, Wollongong, NSW 2522, Australia

"Corresponding author: Brett Williams williamsb@shoalhaven.nsw.gov.au

http://dx.doi.org/10.14453/isngi2013.proc.50
} 
intensifying land use, or conversely target areas of poor accessibility by seeking to improve the transport network.

In Australian local government transport practitioners rely upon various standards and guidelines developed by state and national regulatory bodies to develop best practice in transport management, and by adopting certain unified performance objectives this allows practitioners to work towards consistent outcomes across different jurisdictions. However the benefits of considering accessibility, which combines both land use planning and the transport system that serves it, are not effectively exploited in the standards, policies and guidelines that are currently available.

Critical analysis of the existing literature suggests that accessibility can be a powerful measure to inform practitioners when making decisions on land use planning if developed effectively. Considering the current widespread availability and use of transport modelling software, practitioners and in turn the broad community would benefit from a unified accessibility performance measure that applies not only to metropolitan areas, but also to regional and rural areas. The literature reviewed in this paper confirms the lack of integration between theory and practice, especially in non-metropolitan areas, as well as identifies existing accessibility measures that can be analysed further, to investigate the utilisation of accessibility as an effective and transferable measure for practitioner utilisation with a focus on non-metropolitan areas.

\section{Defining Accessibility}

Accessibility in the context of transport analysis is defined in abundance throughout the relevant literature which dates back over half a century. Whilst its definition is generally consistent, care should be taken to clearly identify its function when discussed. One example describes accessibility as being 'determined by the spatial distribution of potential destinations, the ease of reaching each destination, and the magnitude, quality, and character of the activities found there' ${ }^{2}$.

Focussing on passenger transport, accessibility is defined as the extent to which land use and transport systems enable individuals, or groups of individuals, to reach destinations by means of a combination of transport modes ${ }^{3}$. Delving into the concept of social participation, accessibility is considered to be vital to the liveability of an area, and its economic, social and environmental well being, whilst also concerning the ability of an individual to obtain goods and services, participate in the workforce, interact in the community and undertake recreational pursuits ${ }^{4}$. Paez, Scott and Morency ${ }^{5}$ also offer a brief definition of accessibility as 'the potential for reaching spatially distributed opportunities (for employment, recreation, social interaction, etc.)', however expand this concept by categorising accessibility as being either normative (prescriptive), or positive (descriptive) when considering measures used to address substantive planning and policy questions. The distinction being made is that normative accessibility considers 'how far people ought to travel or how far it is reasonable for people to travel', whereas positive accessibility considers 'how far people actually travel'. The significance of this dichotomy, which has not been clearly defined in previous literature, is that accessibility should also consider the actual experiences of individuals (and possibly their perceptions), as opposed to only being based on assumptions of what is deemed reasonable. 
In Australia recent developments on accessibility have been led by Austroads and the Australian Road Research Board (ARRB), who have combined to produce a research report with the purpose of developing an accessibility assessment framework for policy analysis and performance monitoring ${ }^{1}$. This report states that accessibility 'measures the ease with which people are able to find and reach the best suited opportunity, either for work, study and others', and covers the transport modes of car, public transport, walking and cycling. In a separate paper authored by the ARRB staff who contributed to the above Austroads Research Report, they define accessibility as combining 'land use and transport together like two sides of a coin' 6 .

Another perspective on accessibility is that people value both destination convenience and choice, and that the value placed by people on the ability to access a particular destination is unique for different people and destination types ${ }^{7}$. The examples provided above demonstrate that ample literature regarding the concept of accessibility is available. However, some alternative definitions should also be considered to best understand accessibility. In an earlier Austroads publication it is reported $d$ that accessibility 'is always understood to be the ease of getting to something, and the various uses of the term differ in the types of things that can be reached', however confusion has arisen when considering 'access' as opposed to accessibility $^{8}$. Generally access refers to physical mobility, such as people with disabilities in the context of design (such as the provision of ramps and dedicated parking spaces), and care should be taken to clarify the context of the subject matter when the term accessibility is being used to eliminate any potential ambiguity. An example of this reinforcement is provided by Geurs and van Wee ${ }^{3}$, who qualify their paper by stating ' $[\mathrm{h}] \mathrm{ere}$, access is used when talking about a person's perspective, accessibility when using a location's perspective'. Conversely, an alternative way to study accessibility is to consider its reciprocal, which is defined as 'remoteness' when analysing regional and rural areas'.

\section{Integration of Theory and Policy}

A common theme encountered in literature is the lack of effective integration between accessibility in theory and its use in transportation and land use planning practice. Handy and Niemeier ${ }^{2}$ state that whilst the concept of accessibility is used in the language of planners, it has rarely been transformed into performance measures for the evaluation of policies and has had little practical impact. Similarly in another study that explores the use of quality of life as an accessibility indicator, when used by governments and local partnerships it was found that these indicators tend to be developed in accordance with policy or politically-motivated targets, with minimal consideration of individuals' perception and the eventual outcomes ${ }^{10}$.

Furthermore Paez et al. ${ }^{5}$ report that effective use of accessibility in planning 'has been hampered in the past by limited understanding of the measures, definitional issues, and measurement problems', and have 'led to the use in practice of simple but partial performance measures'. Their consideration of normative versus positive accessibility measures is significant, as this addresses the deficiencies of policy when it is based purely on assumptions or antiquated conventions reproduced from existing literature - the danger here being the automatic assumption of legitimacy when a fact is presented in peer-reviewed literature. This reinforces the need to consider the positive aspects of accessibility sourced from the real activities performed by individuals when using transport, and even their perceptions of how they use it. 
There are however some examples of accessibility measures being used effectively. In one case a tool available through the website of Sutherland Shire Council ${ }^{11}$ offers a mapped Accessibility Index based on walking and public transport opportunities for each parcel of land in the Council's local government area. This Accessibility Index was developed following the Council's desire to address accessibility issues and included data obtained from a telephone survey of residents to ensure that the index reflected the community's opinion ${ }^{4}$. Whilst clearly a useful tool for residents and visitors to the Sutherland Shire, in its current form it would have limited benefit in regional and rural areas where there is often a lack of public transport, walking and cycling opportunities due to dispersed urban development.

Another example of effective use of accessibility as a measure involved a coalition of organisations called the Sydney Alliance who commissioned the development of maps to explore inequality on Sydney's public transport network, which was reported on ABC News Online $^{12}$. This study demonstrated that whilst a considerable proportion of the population lived in close proximity to public transport opportunities, only a small number of locations had services available every 15 minutes or less, thus emphasising a potential aspect of the transport network that could be improved.

Austroads provides some guidance on how the development of accessibility based network performance measures can help assess networks in terms of specific policies ${ }^{8}$. However this report is based on the evaluation of the whole of Australia and is unlikely to be suitable for detailed analysis of smaller study areas, and may be considered to be out of date given the increased performance of computing power available in the intervening years. The Austroads research report on the Application of Accessibility Measures however offers strong potential to provide a unified accessibility measure, named the ARRB Accessibility Metric (AAM), for Australian practitioners, based on four land use 'opportunities', and four travel modes as shown in Table 1.

Table 1. ARRB Accessibility Metric Inputs- reproduced from the Austroads research report on the Application of Accessibility Measures (2011)

\begin{tabular}{|c|c|}
\hline Opportunities & Travel Modes \\
\hline Jobs for employment & Car \\
\hline Enrolment for school & Public Transport \\
\hline Workers in the retail industry & Walk \\
\hline Workers in the recreation industry & Cycle \\
\hline
\end{tabular}

The Austroads report compares the AAM against two other accessibility measures, however it is notable that both of the case-studies used to test these measures were state capital cities Melbourne and Perth, and no detail was provided on the potential to utilise this measure in non-metropolitan areas where public transport, walking and cycling options can be limited.

\section{Accessibility Measures in Non-Metropolitan Areas}

As is the case with most theoretical literature and policy from higher-order authorities, the focus tends to be on the major metropolitan areas, due to the general perception that the problems are a greater issue where population densities and infrastructure utilisation is higher. Handy and Niemeier ${ }^{2}$ provide a comprehensive review on the history of accessibility measures, however the authors appear to consider accessibility as an issue affecting only 
metropolitan areas. Furthermore, a key attribute of the Accessibility Constraints Map developed for Sutherland Shire Council is its ability to be transferable to other Councils, although as previously raised this would have limited benefit in non-metropolitan areas ${ }^{4}$.

In the Austroads Guide to Transport Planning, it is reported that 'there are few planning guidelines that have been separated for urban and rural areas at the national, state/territory and local government level', and that the most obvious differences when comparing urban and rural communities 'are those related to access and affordability' ${ }^{13}$. Whilst also stating that transportation planning needs to consider the many barriers to access that currently exist for rural communities, and the difference in the characteristics of these barriers when compared to urban dwellers, it is noted that other issues need to be considered across the whole transport network (whether urban or rural) such as the long-term strategic consequences of planning actions taken on liveability of locations. Furthermore, the Austroads report on rural accessibility provides an example of applying a basic accessibility measure across the whole of Australia from a broad strategic perspective ${ }^{8}$.

A separate analysis studying rural Australia discusses the perception that there are few problems regarding mobility and accessibility in remote areas, mainly due to a lack of research on the indication of people's ability to overcome the vast distances involved ${ }^{14}$. This paper defined rural areas as those with settlements having a population less than 5,000, which was based on the lowest level of 'service centre' defined in the Accessibility/Remoteness Index of Australia (ARIA) scores developed by the Federal Department of Health and Ageing.

Another study involving remote communities performed vulnerability analysis of regional road networks, and suggested use of accessibility indices as metrics for vulnerability ${ }^{9}$. This study also utilised ARIA scores to develop a measure to undertake assessment of the impacts of network degradation, stating that 'there is an important place for regional studies and for planning tools able to assist in analysing the social-economic consequences of network performance on rural populations'.

\section{Conclusion}

The preliminary literature review provided in this paper introduces accessibility as a concept that describes the opportunities available at a particular, discrete location and the available means to travel both to and from these opportunities. Care must be taken to clearly define the use of the term accessibility due to the potential for ambiguity.

It is evident that further work is required to better integrate theoretical transport accessibility into policy for practitioners to investigate the combination of transport and land use, and how they are effectively utilised by a population that displays wide spatial and demographic characteristics. It is clear that there is as a lack of detailed studies into nonmetropolitan areas. There is also the potential for a unified accessibility measure to be developed that allows accessibility to be used consistently across jurisdictions, and effectively inform and improve land use planning decisions in practice. Upon development, this measure is proposed to be investigated as part of a practitioner-based Masters by Research project using the Shoalhaven local government area as a case study, and eventually incorporating these results into the SMART Infrastructure Dashboard ${ }^{15}$. 
The outcome of this research project has the potential to contribute towards the theory of accessibility, especially in non-metropolitan areas, and how it can be better integrated with practice. Subsequently, the development of an effective accessibility measure also has the ability to be utilised by engineering and planning practitioners, leading towards more efficient utilisation of urban lands and improved transport outcomes. In the face of issues such as climate change, continual population growth and the increasing cost of infrastructure, this project has the ability to contribute towards addressing these challenges.

\section{References}

${ }^{1}$ Espada, I., and Luk, J., “Application of Accessibility Measures”, Austroads Research Report AP-R397-11, Sydney, 2011.

${ }^{2}$ Handy, S. L., and Niemeier, D. A., "Measuring Accessibility: An Exploration of Issues and Alternatives", Environment and Planning A, Vol. 29, No. 7, 1997, pp. 1175-1194. http://dx.doi.org/10.1068/a291175

${ }^{3}$ Geurs, K. T., and van Wee, B., "Accessibility Evaluation of Land-Use and Transport Strategies: Review and Research Directions", Journal of Transport Geography, Vol. 12, No. 2, 2004, pp. 127-140. http://dx.doi.org/10.1016/j.jtrangeo.2003.10.005

${ }^{4}$ Koernicke, I., "Accessibility Constraints Mapping for Walking and Public Transport in the Sutherland Shire", Proceedings of the 30th Australasian Transport Research Forum, 2007.

${ }^{5}$ Paez, A., Scott, D. M., and Morency, C., "Measuring Accessibility: Positive and Normative Implementations of Various Accessibility Indicators", Journal of Transport Geography, Vol. 25, 2012, pp. 141-153. http://dx.doi.org/10.1016/j.jtrangeo.2012.03.016

${ }^{6}$ Espada, I., and Luk, J., "Development of an Accessibility Metric and Its Application to Melbourne", Road \& Transport Research: A Journal of Australian and New Zealand Research and Practice, Vol. 20, No. 3, 2011, pp. 55-66.

${ }^{7}$ Rendall, S., and Cockrem, P., "How Much Choice Is Enough? Comparing the Value of Choice for Different Activites", Proceedings of the IPENZ Transportation Group Conference, Dunedin, 2013.

${ }^{8}$ Davidson, P. M. B., and Davidson, K. B., Assessment Techniques and Tools for Rural Accessibility, Sydney: Austroads Incorporated, 1999.

${ }^{9}$ Taylor, M. A. P., and Susilawati, "Remoteness and Accessibility in the Vulnerability Analysis of Regional Road Networks", Transportation Research Part A-Policy And Practice, Vol. 46, No. 5, 2012, pp. 761-771. http://dx.doi.org/10.1016/j.tra.2012.02.008

${ }^{10}$ Doi, K., Kii, M., and Nakanishi, H., “An Integrated Evaluation Method of Accessibility, Quality of Life, and Social Interaction:, Environment and Planning B-Planning \& Design, Vol. 35, No. 6, 2008, pp. 1098-1116. http://dx.doi.org/10.1068/b3315t

${ }^{11}$ Sutherland Shire Council, Shiremap - Sutherland Shire Council, URL: http://www.sutherlandshire.nsw.gov.au/General/Shiremap

${ }^{12} \mathrm{ABC}$ News Online, Mapping highlights Sydney transport inequality, URL: http://www.abc.net.au/news/2012-11-11/study-reveals-sydneys-public-transportblackspots/4365242

${ }^{13}$ Tsolakis, D., Naude, C., and Evans, C., Guide to road transport planning, Austroads, Sydney, 2009.

${ }^{14}$ Nutley, S., "Indicators of Transport and Accessibility Problems In Rural Australia", Journal of Transport Geography, Vol. 11, No. 1, 2003, pp. 55-71. http://dx.doi.org/10.1016/S0966-6923(02)00052-2

${ }^{15}$ University of Wollongong, SMART SID Project, URL: http://smart.uow.edu.au/projects/UOW145700.html 